\title{
Increased risk of chikungunya infection in travellers to Thailand during ongoing outbreak in tourist areas: cases imported to Europe and the Middle East, early 2019
}

Emilie Javelle ${ }^{1,2,3}$, Simin-Aysel Florescu ${ }^{4}$, Hilmir Asgeirsson ${ }^{5,6}$, Shilan Jmor $^{7}$, Gilles Eperon ${ }^{8}$, Eyal Leshem ${ }^{9}$, Johannes Blum ${ }^{10}$, Israel Molina ${ }^{11}$, Vanessa Field $7{ }^{72}$, Nancy Pietroski ${ }^{13}$, Carole Eldin ${ }^{2}$, Victoria Johnston ${ }^{7}$, Ioana Ani Cotar ${ }^{14}$, Corneliu Popescu ${ }^{4}$, Davidson H Hamer $^{15,16}$, Philippe Gautret ${ }^{2,3}$

1. Laveran Military Teaching Hospital, Marseille, France

2. IHU-Méditerranée Infection, Marseille, France

3. Aix Marseille Université, IRD, AP-HM, SSA, VITROME, Marseille, France

4. Carol Davila University of Medicine and Pharmacy, Clinical Hospital of Infectious and Tropical Diseases 'Dr. Victor Babes', Bucharest, Romania

5. Department of Infectious Diseases, Karolinska University Hospital, Stockholm, Sweden

6. Unit of Infectious Diseases, Department of Medicine Huddinge, Karolinska Institutet, Stockholm, Sweden

7. Hospital for Tropical Diseases, London, United Kingdom

8. Division of Tropical and Humanitarian Medicine, Department of Primary Care, Geneva University Hospitals (HUG), Geneva, Switzerland

9. The Center for Travel and Tropical Medicine, Sheba Medical Center and Sackler Faculty of Medicine, Tel Aviv University, Israel 10. FMH Innere Medizin und Tropen- und Reisemedizin, Schweizerisches Tropen- und Public Health Institut, Basel, Switzerland

11. Department of Infectious Diseases, Hospital Universitari Vall d'Hebron, PROSICS Barcelona, Universitat Autònoma de

Barcelona, Barcelona, Spain

12. Chair of the Tracking and Communications Working Group, GeoSentinel, London, United Kingdom.

13. International Society of Travel Medicine, Dunwoody, United States

14. 'Cantacuzino' National Medico-Military Institute for Research and Development, Bucharest, Romania

15. Department of Global Health, Boston University School of Public Health, Boston, United States

16. Section of Infectious Diseases, Department of Medicine, Boston Medical Center, Boston, United States

Correspondence: Emilie Javelle (emilie.javelle@gmail.com)

Citation style for this article:

Javelle Emilie, Florescu Simin-Aysel, Asgeirsson Hilmir, Jmor Shilan, Eperon Gilles, Leshem Eyal, Blum Johannes, Molina Israel, Field Vanessa, Pietroski Nancy,

Eldin Carole, Johnston Victoria, Cotar loana Ani, Popescu Corneliu, Hamer Davidson H, Gautret Philippe. Increased risk of chikungunya infection in travellers to Thailand during ongoing outbreak in tourist areas: cases imported to Europe and the Middle East, early 2019. Euro Surveill. 2019;24(10):pii=1900146. https://doi. org/10.2807/1560-7917.ES.2019.24.10.1900146

Article submitted on 22 Feb 2019 / accepted on 06 Mar 2019 / published on 07 Mar 2019

We report nine travellers with confirmed chikungunya virus infection, returning from tourist areas of Thailand to Sweden, Switzerland, the United Kingdom, Romania, Israel and France, diagnosed in January and February 2019. These sentinel tourists support the intensification of chikungunya virus circulation in Thailand and highlight the potential for importation to areas at risk of local transmission.

Since the start of 2019, the EuroTravNet/GeoSentinel and TropNet data collection networks for the surveillance of travel-related morbidity have identified nine patients with chikungunya virus (CHIKV) infection imported from Thailand to Sweden, Switzerland, the United Kingdom (UK), Romania, Israel and France. In comparison, the last CHIKV infection reported to EuroTravNet/GeoSentinel in travellers from Thailand was a suspected case in Romania in January 2018. Only three other cases were reported to this network during the past 3 years from Thailand, and none in travellers returning to Europe. Here, we present the clinical and travel data of eight travellers notified to EuroTravNet/ GeoSentinel and one notified to TropNet with confirmed chikungunya disease imported from Thailand within 2 months.

Characteristics of travellers returning from Thailand with chikungunya virus infection The average length of stay of the nine travellers in Thailand was 22 days (range: 10-35 days) and the average delay between arrival in Thailand and onset of chikungunya symptoms was 16 days (range: 5-22 days). Places visited by the travellers in the period before chikungunya onset are shown in the Figure.

The patients' median age was 37 years (range: $14-73$ years), and seven of the nine were female. Underlying conditions were reported in three patients (Table). Acute symptoms included fever and joints pains in all patients, seven had a rash, five reported headache, two had lymphadenitis, five developed oedema or joint swelling (acute thrombophlebitis was excluded in Case 3). Case 8 experienced malaise, fever and loss of consciousness and subsequent head trauma because of the fall. Three patients were hospitalised in Thailand (Cases 1, 3 and 8) and one after returning to their home 
Places of exposure visited by travellers before chikungunya virus infection, Thailand, January-February 2019 (n = 9)

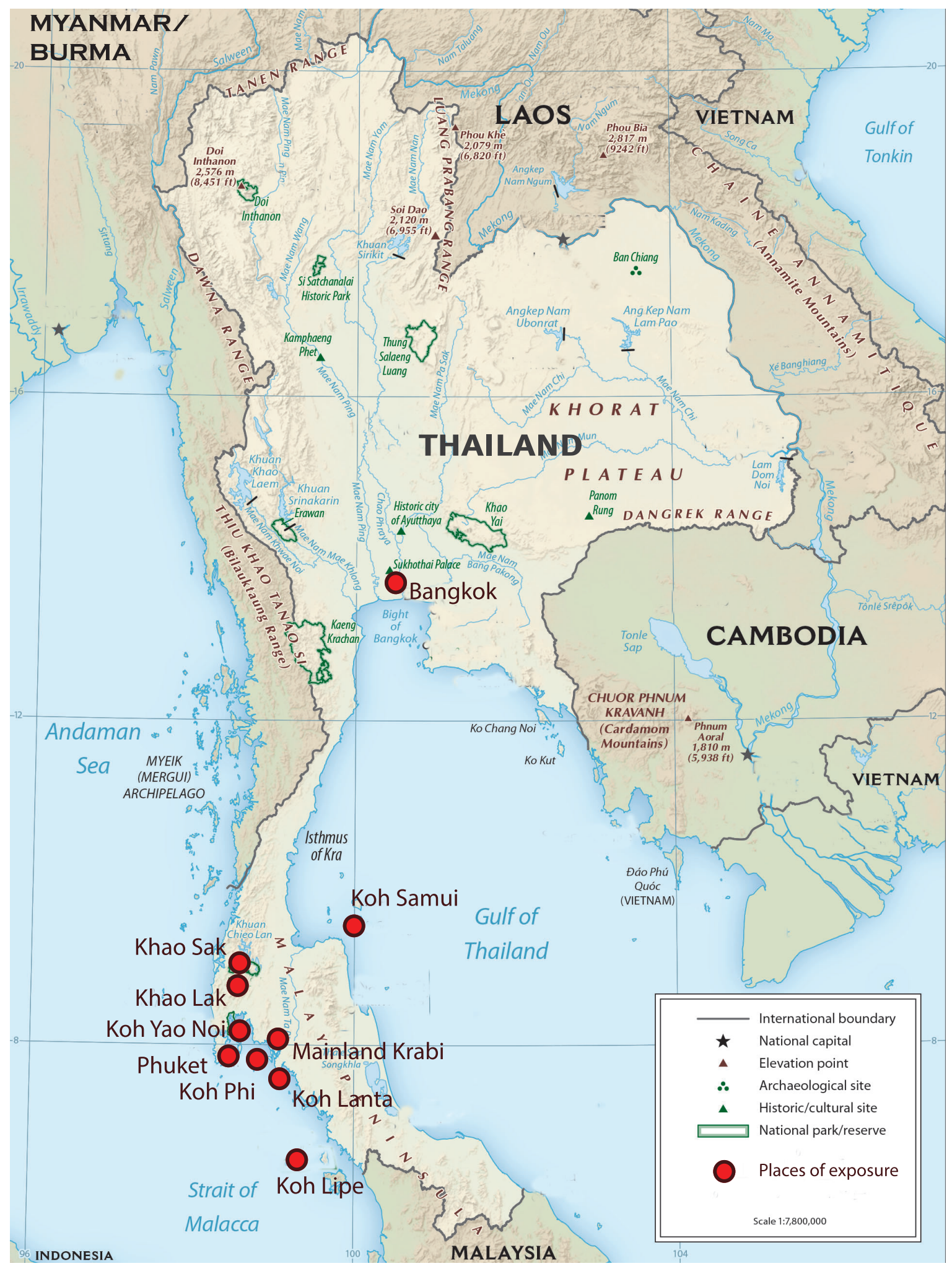

Source: Map from Wikimedia Commons, the free media repository: https://commons.wikimedia.org/wiki/File:Thailand_Physiography.jpg 


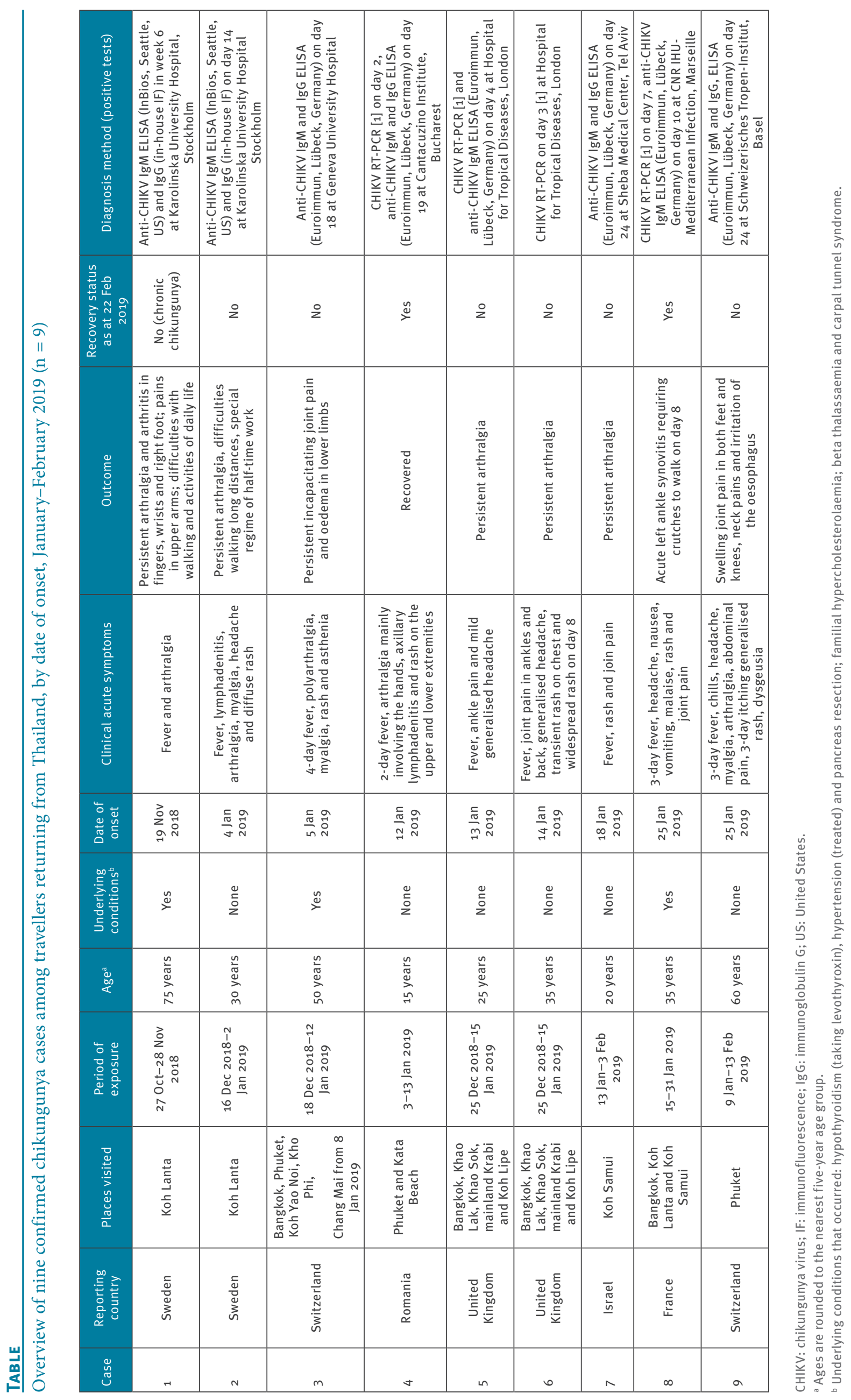


country (Case 4); the remaining five were outpatients. All nine cases were confirmed after their return at the laboratory of the reporting site as detailed in the Table. Alternative diagnoses including arboviral infection with dengue and Zika viruses as well as malaria were ruled out at the time of chikungunya diagnosis using smear tests, dengue virus NS1-antigen, RT-PCR and/or serological tests depending on the delay since onset of symptoms and using tests referenced at the different diagnostic laboratories mentioned in the Table.

Eight of the nine CHIKV-infected travellers received non-steroidal anti-inflammatory drugs (NSAID) for persistent arthralgia. Case 9 was treated with intravenous corticosteroids at the acute stage in Thailand. Only two travellers completely recovered within 3 weeks (Case 4 and Case 8). In contrast, the woman in her 70s (Case 1) developed post-chikungunya chronic rheumatism (lasting more than 3 months). She is heavily impaired in her activities of daily life and has been referred to rheumatology for evaluation.

\section{Simultaneous case of dengue infection imported from Thailand}

A teenage sibling travelling with Case 4 developed fever 4 days before leaving Thailand, followed by a petechial rash, mild arthralgia, nausea, vomiting and mild axillary lymphadenitis. On the day after return to their country of residence, NS 1 antigen was positive for dengue virus and RT-PCR for dengue-1 virus was positive in urine while RT-PCR and serology for CHIKV-infection were negative in serum [1]. Their parents travelling with them have remained asymptomatic.

\section{Discussion}

Beginning in October 2018, the Thai Ministry of Public Health reported a major increase in the number of chikungunya cases in the country. In November alone, 1,132 cases were reported, and by 10 December 2018 , this had risen to 2,143 cases, compared with a total of 10 cases in 2017 [2]. From 1 January to 10 February 2019, 1,652 patients from 17 provinces were reported; mostly affecting Phuket, Pattani, Songkhla, Narathiwat and Phang Nga provinces, with the highest morbidity rate in the southern region [3].

We suspect that all infections in our traveller case series were acquired in southern Thailand. For people who develop symptomatic chikungunya illness, the incubation period is typically 4-7 days (range: 1-12 days) [4]. Bangkok was the point of entry (airport) with a short initial stop for Cases 3, 5, 6 and 8 who developed first symptoms, respectively, 18, 19, 20 and 11 days after their arrival. Case 3 visited Chang Mai in the north of Thailand after the onset of chikungunya symptoms. Two patients developed chikungunya symptoms after spending at least 2 days in Phuket, two others in Koh Samui, and two others in Koh Lanta. One patient became symptomatic after returning to his country of residence.
These nine confirmed cases demonstrate that travellers are currently at risk of CHIKV infection in many tourist areas in southern Thailand. Only one of them had received pre-travel advice. Furthermore, in September 2018, there was a report to EuroTravnet/GeoSentinel of a suspected chikungunya case in a traveller returning from Malaysia to Spain, and chikungunya cases are currently reported from the Malaysian Ministry of Health [5], indicating an extension of this outbreak to neighbouring Asian countries. Given the global traffic to South East Asia, and Thailand in particular [6], there is a need to raise awareness to travellers and healthcare providers about the risk of arboviral diseases.

As confirmed by local sources [7], Case 4 and her sibling attest that CHIKV and the endemic dengue virus are co-circulating in Thailand. The weekly number of dengue fever cases in Thailand seems similar to those recorded in 2018 at the same period with around 150 cases per week in the South [8]. Furthermore, 15 dengue cases have been recorded in the GeoSentinel database in travellers returned from Thailand since the start of 2019 .

Prescription of NSAID for suspected arboviral disease imported from South East Asia should be contraindicated when it is not possible to differentiate between dengue and chikungunya viruses, to avoid haemorrhagic complications. Besides, these are known to be more severe in patients with co-infections $[9,10]$. In addition, careful attention to adequate hydration is essential to minimise feelings of light-headedness and malaise [4].

A distinguishing characteristic of CHIKV infection, in contrast to dengue, are prolonged musculoskeletal disorders [11]. In this case series, all adult women developed long-lasting joint pains; these symptoms were worst in the oldest case (Case 1) and in Case 9 who was treated early in her disease course with corticosteroids, which are not recommended because of the rebound effect after withdrawal [4]. The management of persistent pains relies mainly on a complete therapeutic dose of NSAID after the acute febrile stage, in combination with physical and rehabilitation medicine [4]. Populations at higher risk of complications, including women older than 40 years, persons with underlying rheumatic diseases and athletes, who are planning travel to Thailand and neighbouring countries, should be made aware of the risk of disabilities [11] and of the need for all-day preventive measures against vectors using physical (clothing, bed nets) and chemical (topical repellents with DEET and permethrin impregnations) barriers [12].

The competent vector Aedes albopictus has become widely established in some parts of Europe and Israel since 1979. In 2006, CHIKV was first imported into Europe from outbreaks in the Indian Ocean [13]. Consequently, these locations are at risk of introduction and potential epidemics $[14,15]$. 
Ae. albopictus can transmit CHIKV strains to a varying degree, depending on the viral genome and environmental temperature [16]. There are three main genotypes of CHIKV: Asian, West African and East/Central/ South African (ECSA). The Asian CHIKV, which is more easily transmitted by Ae. aegypti, caused the first documented outbreak in Thailand in 1958 [17] and has regularly circulated in South East Asia in recent years. However, it was an ECSA-mutated virus, well adapted to Ae. albopictus, that emerged on islands in the Indian Ocean in 2005 , spread to Asia and was subsequently responsible for the re-emergence of chikungunya in Thailand in 2008 [18]. Autochthonous transmission events, following ECSA-CHIKV introductions through viraemic travellers, have occurred in Italy in 2007 and 2017 [19] and in France in 2010, 2014 and 2017 [20]. Therefore, determining the CHIKV strain currently circulating in Thailand is of importance to assess the risk of local transmission in Europe, especially before the period of seasonal activity of the vector Ae. albopictus.

\section{Conclusion}

These nine cases, occurring over a period of 2 months, indicate a rise in the number of travel-associated CHIKV infections in southern Thailand with a risk of importation to Europe. At the same time, they illustrate the long-term burden of chikungunya infection. Awareness among clinicians, information and appropriate management of travellers returning from Thailand and neighbouring countries, as well as early detection of imported cases and immediate mosquito control strategies, are vital for preventing CHIKV dissemination and related morbidity.

\section{Acknowledgements}

We would like to acknowledge Geta Vancea; CorneliaSvetlana Ceianu from 'Cantacuzino' National MedicoMilitary Institute for Research and Development, Romania; Gilda Grard and Isabelle Leparc-Goffart from the French National Reference Laboratory for arboviruses, Marseille, France; all participating TropNet's, EuroTravNet's and or Geosentinel Sites' Directors including in alphabetical order François Chappuis, Andreas Neumayr, Adrián Sánchez and Eli Schwartz; and Julien Ripamonti for his help with the map.

The molecular assay in the Romanian patient was funded through CCCDI-UEFISCDI project PN-III-P1.2PCCDI-2017-0005/2018. GeoSentinel, the Global Surveillance Network of the International Society of Travel Medicine (ISTM), is supported by a cooperative agreement (U50CKo0189) from the Centers for Disease Control and Prevention, International Society of Travel Medicine, and Public Health Agency of Canada.

\section{Conflict of interest}

None declared.

\section{Authors' contributions}

Carole Eldin, Simin-Aysel Florescu, Corneliu Popescu, Ani loana Cotar, Hilmir Asgeirsson, Gilles Eperon, Eyal Leshem,
Shilan Jmor, Victoria Johnston, Johannes Blum, Israel Molina, Vanessa Field and Nancy Pietroski provided travel history as well as clinical and biological information on the travellers. Emilie Javelle created the first draft of the manuscript and modified it according to the editorial team's comments. Emilie Javelle, Vanessa Field, Davidson H. Hamer and Philippe Gautret reviewed and edited the manuscript. All authors provided input and reviewed the final version of the manuscript.

\section{References}

1. Pastorino B, Bessaud M, Grandadam M, Murri S, Tolou HJ, Peyrefitte CN. Development of a TaqMan RT-PCR assay without RNA extraction step for the detection and quantification of African Chikungunya viruses. J Virol Methods. 2005;124(12):65-71. https://doi.org/10.1016/j.jviromet.2004.11.002 PMID: 15664052

2. Bureau of Epidemiology, Ministry of Public Health, Thailand (MoPH). National disease surveillance (Report 506, 4861): Chikungunya. Mueang Nonthaburi District: MoPH; 2018. Available from: http://www.boe.moph.go.th/boedb/ surdata/506wk/y61/en/d84_4861_en.pdf

3. Bureau of Epidemiology, Ministry of Public Health, Thailand (MoPH). National disease surveillance (Report 506, 5262): Chikungunya. Mueang Nonthaburi District: MoPH; 2019. Available from: http://www.boe.moph.go.th/boedb/ surdata/506wk/y62/en/d84_0562_en.pdf

4. Simon F, Javelle E, Cabie A, Bouquillard E, Troisgros O, Gentile $\mathrm{G}$, et al. French guidelines for the management of chikungunya (acute and persistent presentations). November 2014. Med Mal Infect. 2015;45(7):243-63. https://doi.org/10.1016/j. medmal.2015.05.007 PMID: 26119684

5. Malay Mail. Health DG: Selangor records highest number of Chikungunya cases. Petaling Jaya: Dato' Siew Ka Wai; 2019. Available from: https://www.malaymail.com/news/ malaysia/2019/02/09/health-dg-selangor-records-highestchikungunya-cases/1721275

6. Glaesser D, Kester J, Paulose H, Alizadeh A, Valentin B. Global travel patterns: an overview. J Travel Med. 2017;24(4). https:// doi.org/10.1093/jtm/taxo07 PMID: 28637267

7. Bureau of Epidemiology, Ministry of Public Health, Thailand (MoPH). National disease surveillance (Report 506, 0362): Dengue fever. Mueang Nonthaburi District: MoPH; 2019. Available from: http://www.boe.moph.go.th/boedb/ surdata/506wk/y62/en/d66_0362_en.pdf

8. Bureau of Epidemiology, Ministry of Public Health Thailand (MoPH). National disease surveillance (Report 506, 3861): Dengue fever. Mueang Nonthaburi District: MoPH; 2018. Available from: http://www.boe.moph.go.th/boedb/ surdata/506wk/y61/en/d66_3861_en.pdf

9. Edwards T, Signor LDCC, Williams C, Donis E, Cuevas LE, Adams ER. Co-infections with chikungunya and dengue viruses, Guatemala, 2015. Emerg Infect Dis. 2016;22(11):20035. https://doi.org/10.3201/eid2211.161017 PMID: 27767914

10. Rosso F, Pacheco R, Rodríguez S, Bautista D. [Co-infection by Chikungunya virus (CHIK-V) and dengue virus (DEN-V) during a recent outbreak in Cali, Colombia: Report of a fatal case]. Rev Chilena Infectol. 2016;33(4):464-7. https://doi.org/10.4067/ S0716-10182016000400013 PMID: 27905632

11. van Aalst M, Nelen CM, Goorhuis A, Stijnis C, Grobusch MP. Long-term sequelae of chikungunya virus disease: $A$ systematic review. Travel Med Infect Dis. 2017;15:8-22. https://doi.org/10.1016/j.tmaid.2017.01.004 PMID: 28163198

12. Public Health Agency of Canada. CATMAT Statement: Measures to Prevent Arthropod Bites. Canada Communicable Disease Report Monthly (CCDR). 2012;38 ACS-3. Available from: https://www.canada.ca/en/public-health/services/reportspublications/canada-communicable-disease-report-ccdr/ monthly-issue/2012-38/statement-on-personal-protectivemeasures-prevent-arthropod-bites.html

13. Pfeffer M, Löscher T. Cases of chikungunya imported into Europe. Euro Surveill. 2006;11(3):E060316.2. PMID: 16807489

14. Leta S, Beyene TJ, De Clercq EM, Amenu K, Kraemer MUG, Revie CW. Global risk mapping for major diseases transmitted by Aedes aegypti and Aedes albopictus. Int J Infect Dis. 2018;67:25-35. https://doi.org/10.1016/j.ijid.2017.11.026 PMID: 29196275

15. Leshem E, Bin H, Shalom U, Perkin M, Schwartz E. Risk for emergence of dengue and chikungunya virus in Israel. Emerg Infect Dis. 2012;18(2):345-7. https://doi.org/10.3201/ eid1802.111648 PMID: 22305194

16. Vega-Rúa A, Lourenço-de-Oliveira R, Mousson L, Vazeille M Fuchs S, Yébakima A, et al. Chikungunya virus transmission 
potential by local Aedes mosquitoes in the Americas and

Europe. PLoS Negl Trop Dis. 2015;9(5):e0003780. https://doi. org/10.1371/journal.pntd.0003780 PMID: 25993633

17. Hammon WM, Rudnick A, Sather GE. Viruses associated with epidemic hemorrhagic fevers of the Philippines and Thailand. Science. 1960;131(3407):1102-3. https://doi.org/10.1126/ science.131.3407.1102 PMID: 14399343

18. Rianthavorn P, Prianantathavorn K, Wuttirattanakowit N, Theamboonlers A, Poovorawan Y. An outbreak of chikungunya in southern Thailand from 2008 to 2009 caused by African strains with A226V mutation. Int J Infect Dis. 2010;14(Supp 3):e161-5. https://doi.org/10.1016/j.ijid.2010.01.001 PMID: 20417142

19. Vairo F, Mammone A, Lanini S, Nicastri E, Castilletti C, Carletti $F$, et al. Local transmission of chikungunya in Rome and the Lazio region, Italy. PLoS One. 2018;13(12):e0208896. https:// doi.org/10.1371/journal.pone.0208896 PMID: 30576334

20. Calba C, Guerbois-Galla M, Franke F, Jeannin C, Auzet-Caillaud $M$, Grard G, et al. Preliminary report of an autochthonous chikungunya outbreak in France, July to September 2017. Euro Surveill. 2017;22(39):17-00647. https://doi.org/10.2807/15607917.ES.2017.22.39.17-00647 PMID: 29019313

\section{License, supplementary material and copyright}

This is an open-access article distributed under the terms of the Creative Commons Attribution (CC BY 4.0) Licence. You may share and adapt the material, but must give appropriate credit to the source, provide a link to the licence and indicate if changes were made.

Any supplementary material referenced in the article can be found in the online version.

This article is copyright of the authors or their affiliated institutions, 2019. 